\title{
Breast cancer susceptibility gene 1 (BRCA1) predict clinical outcome in platinum- and toxal-based chemotherapy in non-small-cell lung cancer (NSCLC) patients: a system review and meta-analysis
}

\author{
Yanlong Yang ${ }^{1 \dagger}$, Yuanliang $\mathrm{Xie}^{2+}$ and Lei Xian ${ }^{1 *}$
}

\begin{abstract}
The recent studies have evaluated the relationship between BRCA1 expression and clinical outcome of chemotherapy (mainly focused on platinum-based and toxal-based treatment) in NSCLC patients, but the results were inconclusive and controversial. Our aim of this study was to evaluate this association by literature based system review and meta-analysis.

PubMed, EMBASE and the China National Knowledge Infrastructure (CNKI) databases were used to retrieve the relevant articles. The interested outcome included objective response rate (ORR), overall survival (OS) and event-free survival (EFS). The pooled odds ratio (OR) or hazard ratio (HR) with 95\% confidence interval (Cl) ware estimated. After specific inclusion and exclusion criteria, 23 studies fulfilled the criteria and were included in our analysis. In 17 platinum-based studies, low/negative $B R C A 1$ was in favor of better $\mathrm{ORR}(\mathrm{OR}=1.70,95 \% \mathrm{Cl}=1.32-2.18)$, longer OS and $\mathrm{EFS}(\mathrm{HR}=1.58,95 \% \mathrm{Cl}=1.27-1.97$, and $\mathrm{HR}=1.60,95 \% \mathrm{Cl}=1.07-2.39$ for $\mathrm{OS}$ and $\mathrm{EFS}$, respectively). In 4 toxal-based chemotherapy studies, the patients with high/positive BRCA1 had better ORR (OR=0.41,95\% $\mathrm{Cl}=0.26-0.64)$, OS and EFS were not evaluated as the insufficient data available.

Overall, BRCA1 might be a useful biomarker to predict clinical outcome for personal chemotherapy in NSCLC patients in the future.
\end{abstract}

Keywords: BRCA1, NSCLC, Platinum, Toxal, Meta-analysis

\section{Introduction}

Lung cancer is now the most commonly diagnosed cancer and the leading cause of cancer death worldwide [1]. In USA, 412,230 cases had lung cancer history and the new cases estimated in 2012 were 226,160. Most of lung cancers (56\%) are diagnosed at an advanced stage as the typically asymptomatic in early stage. Lung cancer is classified into primarily two subgroups: small-cell lung cancer (SCLC) and non-small-cell lung cancer (NSCLC), and the later

\footnotetext{
*Correspondence: Xianlei59@163.com

${ }^{\dagger}$ Equal contributors

'Department of Cardiothoracic Surgery, the First Affiliated Hospital of Guangxi Medical University, Nanning, Guangxi Zhuang Autonomous Region 530021, China

Full list of author information is available at the end of the article
}

accounts for approximately $85 \%$ of all lung cancers. Although the notable progress has been made in lung therapy, this disease is still associated with a poor prognosis and has few effective treatment options. The overall 5-year survival rate for NSCLC is $17.1 \%$ [2].

The chemotherapy efficacy is varied from different individual, even in patients with similar clinical and pathologic features, the outcome varies: some complete released, some are stable or even progression. So some authors consider NSCLC as a heterogeneous disease [3]. The genetic factor may contribute greater to this diverse efficacy, the SNPs or gene expression products (mRNA and protein) could be special biomarkers. As the development of biochemistry, some notable biomarkers such as EGFR, VEGF, were identified to predict lung cancer treatment outcome, breast

\section{Biomed Central}


cancer susceptibility gene 1 (BRCA1) has emerged as one of the most appealing genetic markers among them.

$B R C A 1$ located in chromosome $17 \mathrm{q} 21$, and was identified as a breast and ovarian cancer susceptibility gene. BRCA1 germline mutations have been correlated to the increasing risk of developing breast and ovarian cancer [4,5]. Recent studies have shown that the protein encoded by this gene is a nuclear phosphoprotein and has multiple roles not only in DNA damage repair but also in cell cycle checkpoint or cell death machinery [6,7]. A greater sensitivity to cisplatin with decreased BRCA1 mRNA expression and a greater resistance to the paclitaxel with increased BRCA1 mRNA expression was observed in breast cancer cell lines $[7,8]$. Also in tumour cells isolated from malignant effusions of NSCLC and gastric cancer patients, the same effect was observed [9].

Followed by in vitro studies, clinical studies explored this relationship. Taron et al. [10] firstly examined the potential role of BRCA1 mRNA expression in predicting differential chemotherapy sensitivity in NSCLC, and found the patients with high BRCA1 had poor outcome while those with low had better outcome. Followed by Taron, a series of studies evaluated the relationship between BRCA1 level and chemotherapy outcome. The chemotherapy regimens were mainly focused on platinum-based and toxal-based treatment. However, the results were inconclusive due to the limited sample size and the limited statistics power. Current study provided a comprehensive assessment on the association between BRCA1 level and the platinum- and toxal-based chemotherapy in NSCLC using meta-analysis.

\section{Materials and methods}

\section{Literature search}

Relevant studies were searched in PubMed, EMBASE and China National Knowledge Infrastructure (CNKI) databases using the following terms: "BRCA1 or Breast cancer susceptibility gene 1 or Breast cancer 1 " and "NSCLC or non-small-cell lung cancer". The last research time was December 10, 2012.

\section{Inclusion criteria}

The following criteria were used to select publications: (1) studies published in English and Chinese regardless of publication time; (2) reviews, animal or cell line studies should be excluded; (3) the NSCLC patients should be pathologically confirmed; (4) BRCA1 expression should be detected by immunohistochemistry (IHC) or reversetranscriptase polymerase chain reaction (RT-PCR); (5) the studies should provided the clinical outcomes such as objective response rate (ORR) to chemotherapy, overall survival (OS) or event-free survival (EFS) with $\mathrm{HR}$ and 95\%CI, EFS was classified as progression-free survival (PFS), disease-free survival (DFS) and time to progression (TTP).

\section{Data collection}

Publication characteristics details such as first author's name, publication year, patients' original country, sample type, detection method of BRCA1, sample size, middle/ mean age of study sample, disease stage were collected for each eligible publication. End points of interest were objective response rate (ORR), overall survival (OS), and event-free survival (EFS).

\section{Statistical analysis}

To estimated ORR, the patients were divided into responders and non-responders. The responders were defined as complete response $(\mathrm{CR})$ and partial response (PR) and the non-responders including stable disease (SD) and progressive disease (PD). The pooled odds ratio (OR) and its 95\% confidence intervals (CIs) were calculated by the methods proposed by Mantel and Haenszel [11], or by DerSimonian R and Laird N [12]. For time-to-event dataOS and EFS, the hazard ratios (HRs) and associated 95\% confidence interval $(\mathrm{CI})$ were estimated using the methods reported by Parmar [13].

The between study heterogeneity was determined by $\mathrm{Q}$ test and $I^{2}$ metric $\left(I^{2}=0-25 \%\right.$ : no heterogeneity; $I^{2}=25-50 \%$ : moderate heterogeneity; $I^{2}=50-75 \%$ : large heterogeneity; $I^{2}=75-100 \%$ : extreme heterogeneity) [14]. The fixed-effect model was applied in the initial analysis, and if the significant heterogeneity existed, then the confirmed random-effect model was used. Begg's test was used to evaluate the publication bias. $\mathrm{P}<0.05$ indicated significant publication bias [15]. All $P$ value was two-tailed, and STATA version 11.1 (Stata Corporation, USA) was used to perform the most of data analysis.

\section{Results}

\section{Eligible studies}

188 potentially relevant studies were identified through the search strategy. After checking the title and abstract, 134 studies excluded because it was very clear that their design didn't meet our inclusion criteria. Then the full texts of 54 articles were carefully screened, 29 studies were excluded as data insufficiency that we could not extract the data for analysis, 2 studies were excluded for potential data overlap as the same institute conducted the research and their patients recruitment time may exist overlap. Finally, a total of 23 studies were eligible for the final analysis. Among them, 19 studies estimated the relationship between BRCA1 and platinum-based chemotherapy outcome [10,16-33], 3 were toxal-based [34-37]. Additional one studies evaluated the toxal-based in fist-line chemotherapy and a part of patients received platinum-based treatment [36]. The study selection process was showed in Figure 1. 


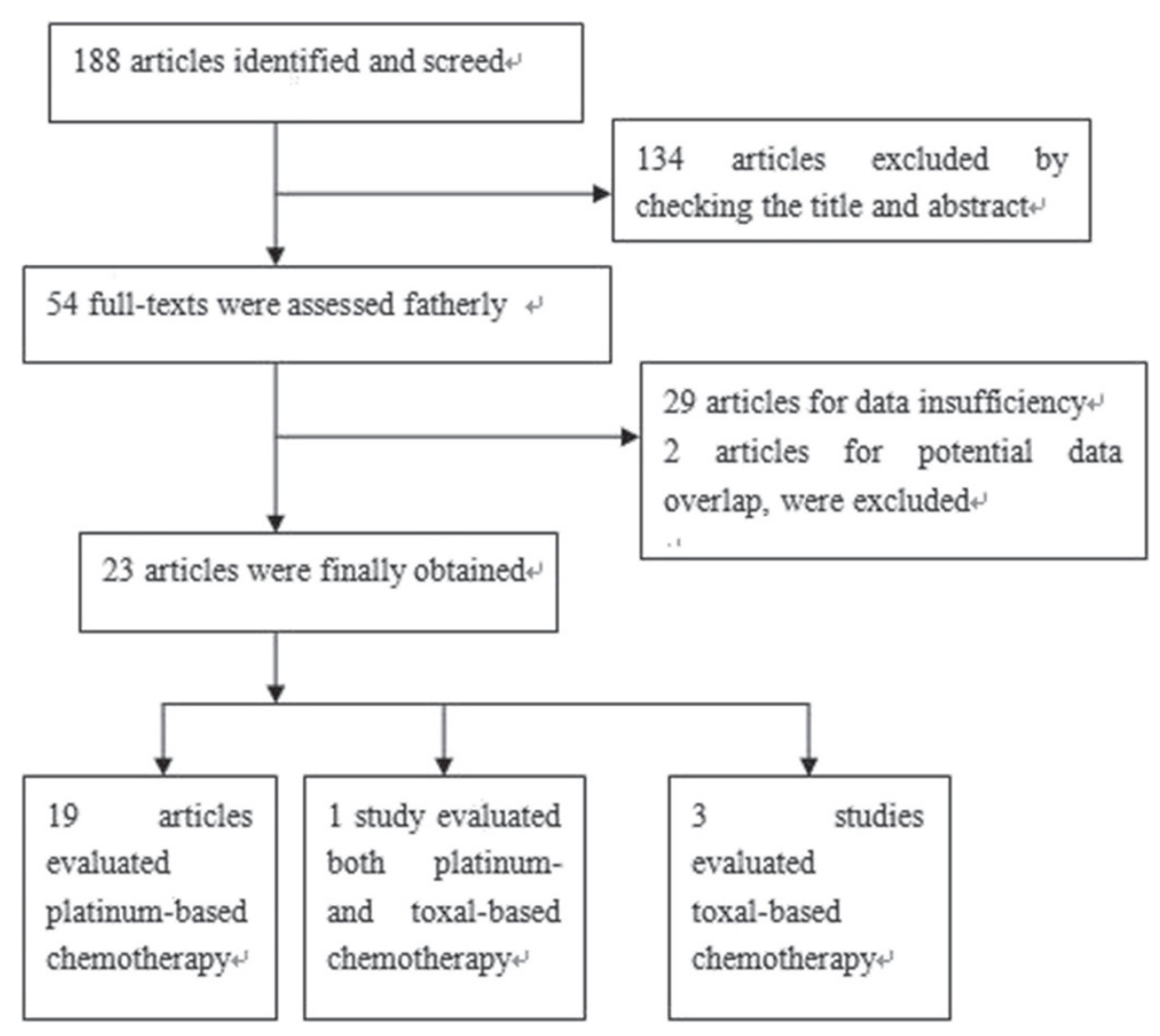

Figure 1 The flow chart of study selection and exclusion.

\section{Study characteristics}

Our meta-analysis composed 23 studies [10,16-37] including 2606 NSCLC patients. The sample size variant from 34 to 769,17 studies were about East-Asian population [16-25,27,28,30,32-34,37], 5 studies were about Caucasian $[10,26,29,35,36]$ and 1 studies may contain different races as the samples were from the prospective randomized clinical trial International Adjuvant Lung Trial (IALT) [31]. In this multi-center study, the author's intention was to investigate the predictive and prognostic role of $B R C A 1$ level in squamous cell carcinoma (SCC) and adenocarcinoma (ADC), so both OS and EFS were conducted in 2 groups (SCC and ADC). Table 1 summarized the main characteristics of included studies.

BRCA1 level and the clinical outcome of chemotherapy The relationship between BRCA1 level and the clinical outcome was presented in Table 2 and Figures 2, 3, 4, 5.

1. Platinum-based chemotherapy

16 studies [10,16-29,33] composed 1330 patients reported the data on ORR. Low/negative BRCA1 expression was observed in 591 patients (account for 44.4\%) and the high/positive expression was in 739 patients (55.6\%). It seemed that patients bearing low/negative $B R C A 1$ had a higher ORR to platinumbased chemotherapy than those bearing high/positive BRCA1 level $(48.9 \%$ vs $38.1 \%$, OR $=1.70,95 \% \mathrm{CI}=$ 1.32-2.18, $I^{2}=44.7 \%, P=0.03$ for heterogeneity) (Figure 2). No publication bias was observed $(P=0.15)$. In subgroup analysis based on BRCA1 detection method, there were 13 IHC studies (1066 patients) $[16,17,19,21-28,33]$ and 4 RT-PCR studies (264 patients) $[10,18,20,29]$, the distribution of low/ negative $B R C A 1$ was similarity(IHC vs RT-PCR: $44.5 \%$ vs $44.3 \%$ ). Both of them found the significant association (for IHC studies, $50.7 \%$ vs $39.0 \%$, $\mathrm{OR}=1.54,95 \% \mathrm{CI}=1.17-2.00, I^{2}=44.8 \%, P=0.03$ for heterogeneity; for RT-PCR studies, $43.7 \%$ vs $25.0 \%, \mathrm{OR}=2.91,95 \% \mathrm{CI}=1.55-3.83, I^{2}=0.0 \%$, $P=0.52$ for heterogeneity), When we stratified studies according to their origin, 13 studies were conducted in East-Asian [16-25,27,28,33] and only 3 were Caucasian $[10,26,29]$. The low/negative $B R C A 1$ level distribution in Caucasian was lower than East-Asian (38.6\% vs $45.4 \%$ ).The significant association was found in East-Asian population rather than Caucasian: for East-Asian, $51.0 \%$ vs $36.0 \%, \mathrm{OR}=1.68,95 \% \mathrm{CI}=1.30-2.19, I^{2}=39.9 \%$, $P=0.04$ for heterogeneity; for Caucasian, $39.8 \%$ 
Table 1 Characteristics of eligible studies evaluating BRCA1 level and clinical outcome

\begin{tabular}{|c|c|c|c|c|c|c|c|}
\hline Study (year) & $\begin{array}{c}\text { Source of } \\
\text { study }\end{array}$ & $\begin{array}{c}\text { No. of } \\
\text { patients }\end{array}$ & $\begin{array}{c}\text { median } \\
\text { age }\end{array}$ & $\begin{array}{c}\text { BRCA1 } \\
\text { detection }\end{array}$ & $\begin{array}{c}\text { Disease } \\
\text { stage }\end{array}$ & Chemotherapy & $\begin{array}{c}\text { Clinical } \\
\text { outcome }\end{array}$ \\
\hline Taron,2004 [10] & Spanish & 60 & NR & RT-PCR & $\|b\|$, & GP & ORR,OS \\
\hline Ota,2009 [16] & Japan & 156 & 62 & $\mathrm{IHC}$ & IV & NP,DC,PI,GP,paclitaxel/carboplatin & ORR, \\
\hline Shang,2009 [17] & China & 60 & 54 & $\mathrm{HC}$ & \|\|\|\| & platinum-based & ORR \\
\hline Yang,2009 [18] & China & 75 & 57 & RT-PCR & IIIB, IV & NP,TP & ORR,OS \\
\hline Shan,2009 [19] & China & 81 & 62 & $\mathrm{HC}$ & IIIB, IV & $N P, G P, T P$ & ORR \\
\hline Wang,2010 [20] & China & 34 & 61 & RT-PCR & IIIB, IV & GP & ORR \\
\hline Lu,2010 [21] & China & 65 & 62.4 & $\mathrm{IHC}$ & IIIB, IV & GP & ORR \\
\hline Mo,2011 [22] & China & 80 & 50 & $\mathrm{IHC}$ & III, IV & GP,NP,TP & ORR \\
\hline Gao,2011 [23] & China & 122 & 60 & $\mathrm{IHC}$ & IIIB, IV & platinum-based & ORR \\
\hline Wan,2011 [24] & China & 87 & 58 & $\mathrm{IHC}$ & $\| \mathrm{IB}, \mathrm{IV}$ & $\mathrm{TP}$ & ORR \\
\hline Zhang,2011 [25] & China & 136 & 61 & $\mathrm{IHC}$ & III, IV & GP,NP,TP & ORR \\
\hline Chen,2011 [33] & China & 152 & NR & $\mathrm{IHC}$ & IIIB, IV & GP,NP,TP & ORR \\
\hline Joerger,2011 [26] & Netherlands & 42 & 59.3 & $\mathrm{IHC}$ & $\| \mathrm{B}, \mathrm{IV}$ & GP & ORR,OS,PFS \\
\hline Fujii,2011 [27] & Japan & 35 & 58 & $\mathrm{HC}$ & III & neoadjuvant chemotherapy and chemoradiotherapy(PI,DC) & ORR,OS \\
\hline $\mathrm{Gu}, 2012[28]$ & China & 50 & NR & $\mathrm{IHC}$ & \|\|\|\| & neoadjuvant chemotherapy(NP,GP) & ORR \\
\hline Papadaki,2012 [29] & Greece & 100 & 63 & RT-PCR & IV & 2nd line PI,Cisplatin,Cisplatin + pemetrexed & ORR,OS,PFS \\
\hline Zeng,2010 [30] & China & 63 & 64 & $\mathrm{IHC}$ & \|\|\|\| & $\mathrm{NP}, \mathrm{GP}, \mathrm{EP}$ & OS \\
\hline Pierceall,2011 [31] & Multi-center & 769 & NR & $\mathrm{HC}$ & \|\|\|\| & platinum-based,no treatment & OS,DFS \\
\hline Leng,2012 [32] & China & 85 & 57 & RT-PCR & \|\|$\|,|,| \mathrm{V}$ & GP,NP,TP & OS,DFS \\
\hline Boukovinas,2008 [36] & Greece & 96 & 60 & RT-PCR & IIIB, IV & 1st line $D G, 2$ nd line platinum-based & ORR,OS,TTP \\
\hline Su,2011 [34] & China & 63 & 60 & RT-PCR & IIIB, IV & toxal-based & OS, \\
\hline Papadaki,2011 [35] & Greece & 131 & 60 & RT-PCR & $\| \mathrm{B}, \mathrm{IV}$ & $\mathrm{DG}, \mathrm{DC}$ & ORR,OS,PFS \\
\hline Zhou,2012 [37] & China & 64 & 58 & $\mathrm{IHC}$ & III, IV & toxal-based & ORR \\
\hline
\end{tabular}

Note: RT-PCR: real-time reverse transcriptase polymerase chain reaction, IHC: immunohistochemistry, GP: gemcitabine/platinum, NP: vinblastine/platinum, DC: docetaxel/cisplatin, PI: platinum/irinotecan, TP: toxal/platinum, NR not reported, PFS: progression-free survival, DFS: disease-free survival, TTP: time to progression.

vs $33.4 \%$, OR $=1.77,95 \% \mathrm{CI}=0.50-6.28, I^{2}=63.6 \%$, $P=0.06$ for heterogeneity. However, the relationship between BRCA1 level and ORR in Caucasian population could not be determined as the sample size was not large enough.

7 studies consisted of 3 East-Asian [18,30,32] and 4. Caucasian $[10,26,29,31]$ including 733 patients were used to analyzed the OS. The significant association between BRCA1 expression and OS in platinum-based treatment was detected. Patients bearing low/negative $B R C A 1$ was more likely to have longer survival time. $(\mathrm{HR}=1.58,95 \% \mathrm{CI}=1.27-1.97$, $I^{2}=48.4 \%, P=0.03$ for heterogeneity) (Figure 3), no publication bias was observed $(P=0.13)$.

EFS data were available for 5 studies $[26,29,31,32,36]$ with 599 patients (3 were PFS [26,29,32], one was DFS [31] and the other one was TTP [36]),only one study was about East-Asian[32]. It seemed that patients with low/negative BRCA1 had longer EFS than those with high level, even there was no publication bias, but heterogeneity existed between studies. $(\mathrm{HR}=1.60,95 \% \mathrm{CI}=1.07-2.39)\left(I^{2}=54.5 \%\right.$, $P=0.02$ for heterogeneity) (Figure 4 ).

2. Taxol-based chemotherapy Since only 2 studies [35,36] presented the sufficient data of OS and EFS that ensured us to conducted meta-analysis. We didn't evaluate the relationship between BRCA1 expression and OS/EFS. In ORR analysis, we applied 4 eligible studies (2 East-Asian and 2 Caucasian) [34-37] in our meta-analysis. A total of 375 patients were included in this comparison. Among 375 patients, 155 patients (account for $41.3 \%$ of total) bared low/negative BRCA1 and the remaining 220 patients (account for $58.7 \%$ of total) bared high/ positive BRCA1. An interesting conclusion was found: opposite to platinum-based treatment, NSCLC patients bearing high/positive $B R C A 1$ were more likely to respond to toxal-based treatment when compared with those bearing the low/negative (low/negative vs high/positive: $26.0 \%$ vs $46.1 \%$, OR $=0.41$, $95 \% \mathrm{CI}=0.27-0.64, \mathrm{I}^{2}=0.0 \%, P=0.61$ for heterogeneity) (Figure 5). No publication bias existed $(P=0.84)$. 
Table 2 The summary meta-analysis results of association between BRCA1 level with objective response rate (ORR), overall survival (OS) and event-free survival (EFS) in platinum- and toxal-based treatment

\begin{tabular}{|c|c|c|c|c|c|c|}
\hline Comparisons & $\begin{array}{c}\text { No of studies } \\
\text { (patients) }\end{array}$ & $\begin{array}{l}\text { Percentage of low/ } \\
\text { negative BRCA1 (\%) }\end{array}$ & $\begin{array}{l}\text { ORR: low/negative } \\
\text { vs high/postive (\%) }\end{array}$ & $\begin{array}{l}\text { Overall OR/HR }(95 \% \mathrm{Cl}) \\
\text { fixed and random }\end{array}$ & $\begin{array}{l}\text { Heterogeneity } \\
\text { test }\end{array}$ & $\begin{array}{c}P \text { for publication } \\
\text { bias }\end{array}$ \\
\hline \multicolumn{7}{|l|}{ Platinum-based } \\
\hline ORR overall & 16(1330) & 44.4 & 48.9 vs 38.1 & $1.70(1.32,2.18), 1.80(1.26,2.55)$ & $P^{2}=44.7 \%, P=0.03$ & 0.15 \\
\hline \multicolumn{7}{|l|}{ Method } \\
\hline $\mathbb{H C}$ & 13(1066) & 44.5 & 50.7 vs 39.0 & $1.54(1.17,2.00), 1.59(1.07,2.36)$ & $P^{2}=44.8 \%, P=0.03$ & 0.41 \\
\hline RT-PCR & $4(264)$ & 44.3 & 43.7 vs 25 & $2.91(1.55,3.83), 2.91(1.55,5.47)$ & $P^{2}=0.0 \%, P=0.52$ & 0.76 \\
\hline \multicolumn{7}{|l|}{ Origin } \\
\hline East-Asian & 14(1133) & 45.4 & 51.0 vs 36.0 & $1.68(1.30,2.19), 1.79(1.24,2.60)$ & $P^{2}=39.9 \%, P=0.04$ & 0.10 \\
\hline Caucasian & $3(197)$ & 38.6 & 39.8 vs 33.4 & $1.79(0.84,3.83), 1.77(0.50,6.28)$ & $P^{2}=63.6 \%, P=0.06$ & 0.90 \\
\hline OS & $8(733)$ & - & - & $1.58(1.27,1.97), 1.65(1.19,2.89)$ & $P^{2}=48.4 \%, P=0.03$ & 0.13 \\
\hline EFS & $6(599)$ & - & - & $1.62(1.28,2.05), 1.60(1.07,2.39)$ & $P^{2}=54.5 \%, P=0.02$ & 0.88 \\
\hline \multicolumn{7}{|l|}{ Toxal-based } \\
\hline ORR overall & $4(376)$ & 41.3 & 26.0 vs 46.1 & $0.41(0.26,0.64), 0.41(0.27,0.64)$ & $P^{2}=0.0 \%, P=0.61$ & 0.84 \\
\hline
\end{tabular}

\section{Discussion}

Although the relationship between $B R C A 1$ expression and chemotherapy outcomes of NSCLC has been investigated by previous studies, the results were inconsistent and some were even conflicting. So a systematic review and metaanalysis based on the published literature was necessary to give further insights on this conflicting issue. Our metaanalysis showed that for platinum-based chemotherapy, low/negative BRCA1 expression were associated with not only better ORR, but also longer OS and EFS, but for toxalbased chemotherapy, high/positive BRCA1 was associated with better ORR.

Platinum agents can bind to DNA and form complexes thus inducing intra- and inter-strand DNA, as well as DNA-protein cross-links and results in cell growth inhibition and apoptosis. As one of ant-tubulin agents, taxol inhibits cell division by enhancing formation and stabilization of microtubules and disrupts the mitotic spindle assembly,

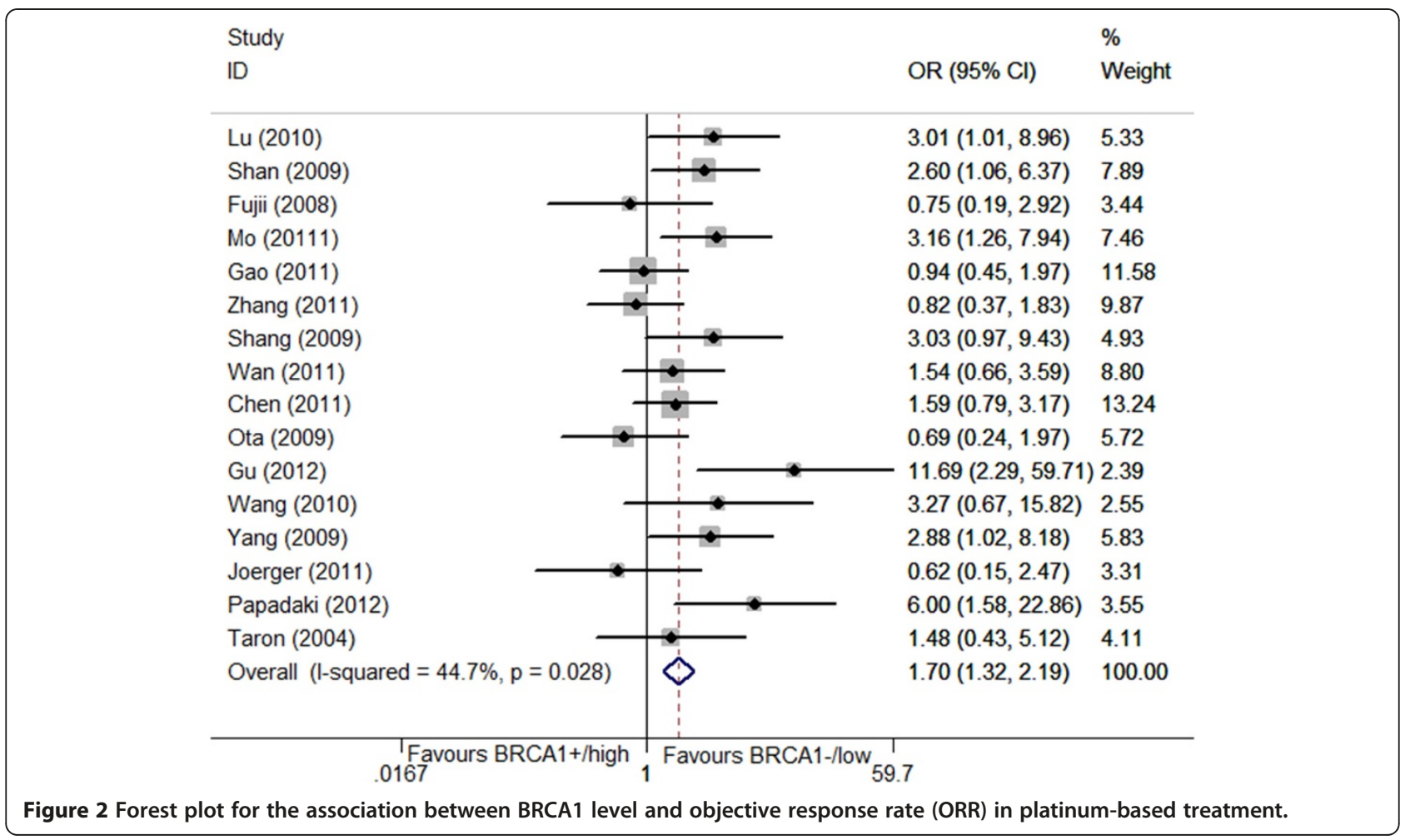


and a surveillance mechanism known as the spindle checkpoint at the metaphase-anaphase transition have been activated. It leads to the abrogation of the spindle checkpoint, results in unequal segregation of chromosomes and aneuploidy [38].

Like excision repair cross complementing 1 (ERCC1), xeroderma pigmentosum group $\mathrm{D}$ and $\mathrm{G}(X P D, X P G)$, $B R C A 1$ belongs to nucleotide excision repair (NER) system [39], which has been reported to be the mayor repair system that reduced platinum-induced DNA damage. BRCA1 involves in homologous recombination, nonhomologous end joining, mismatch repair and other effects though its interaction with other DNA repair gene such as ATM, ATR, RAD51, RAD50, MRE11, NBS1. BRCA2 and so on [7]. The reason that high/positive $B R C A 1$ could predict the good response to taxol is still not clear, 3 mechanisms had been proposed in explained this issue: (1) trigger cell cycle arrest in G2/M phase, (2) enhance apoptosis through a pathway involving H-Ras, MEKK4, JNK, and activation of caspases 8 and 9, (3) participate in spindle assembly checkpoint signaling $[6,40]$.

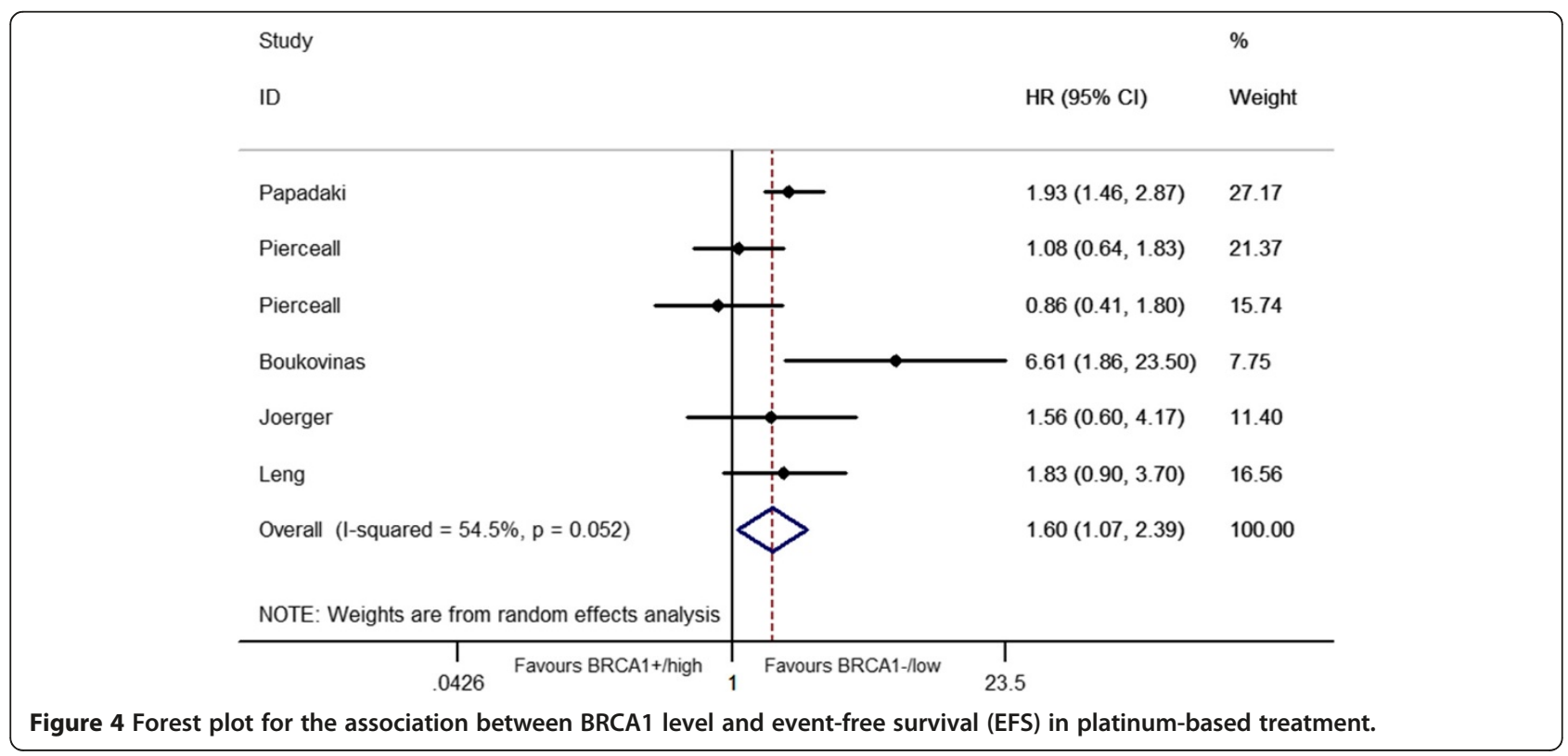




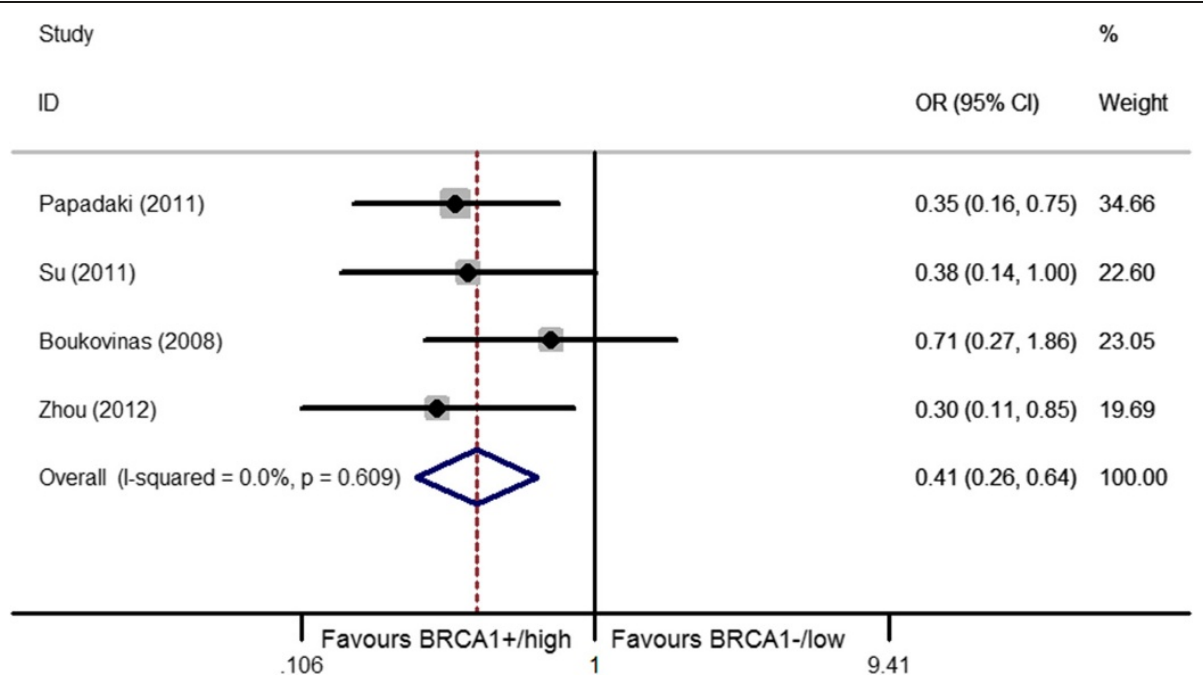

Figure 5 Forest plot for the association between BRCA1 level and objective response rate (ORR) in toxal-based treatment.

BRCA1 gene showed an interesting outcome in NSCLC chemotherapy. Several cell studies and our meta-analysis based on clinical trials demonstrated low/negative BRCA1 expression could benefit from platinum-based chemotherapy; in contrast, the high level of BRCA1 expression was in favor of toxal contained agents. This may confuse us, how could we determine chemotherapy choice properly? Rosell customized treated 84 patients based on their BRCA1 expression: low, cisplatin plus gemcitabine (GP); intermediate, cisplatin plus docetaxel (DC); high, docetaxel alone. The median survival (MS) and 2-year survival of low BRCA1 patients received GP regime was 11 month and $41.2 \%$, which seem to be favorable with the traditional randomized trial treated with GP or pemetrexed plus cisplatin. The MS of high BRCA1 patients received singleagent docetaxel was 11 month and had no detrimental effect when compared with a large phase III trial in patients treated with DC [41]. If this hypothesis is validated, the NSCLC patients with high BRCA1 should receive taxol based and non-platinum-contained adjuvant chemotherapy, which would be more economic, efficacy and less toxic effect for patients. However, more multi-center prospective clinical trials should be conducted to confirm this hypothesis.

Since BRCA1 mRNA and protein level was associated with treatment efficacy, why other biomarkers such as SNPs in this gene could be a choice? But in another hand, it seems that gene expression level provides direct evidence and SNPs provide indirect evidence as it is usually gene product especially protein rather than gene itself play an import role in biochemical activity. Although SNPs are important gene variant that affect the protein expression, but many factors involve in protein synthesis. We found that studies evaluated the SNPs in BRCA1 gene and the clinical outcome was limited. Su [42] found that BRCA1
S1613G was associated with platinum-based chemotherapy efficacy in objective response rate. In a large trail consisted of 300 NSCLC patients at stages III and IV, AACC haplotype but not single S1613G in BRCA1 was associated with poor overall survival (hazard ratio $=2.097 ; 95 \% \mathrm{CI}, 1.339$ to 3.284) treated with platinum combination chemotherapy [43]. However, whether SNPs or haplotypes were associated with clinical outcome was still under debate since lacking of enough evidence.

To interpret the results of meta-analysis, several important acknowledgments should be addressed. First, did the BRCA1 assessment methodology consistently? As we know, IHC detects gene expression at protein level, while RT-PCR assays at mRNA level. From mRNA to protein, many factors such as transcription, post-transcriptional regulation, translation and post-translation may affect this process. Besides, RT-PCR uses the bulk tumor/tissue to extract RNA, while IHC can distinguish cell type and can read protein level only in cancer cell when compared with normal epithelial cell. Even in studies using IHC or RTRCR assessment methodology, their cutoff value was inconsistently. Although in subgroup analysis based on BRCA1 detecting methods in platinum-based treatment, both IHC and RT-PCR showed the significant association between BRCA1 level and ORR, the potential heterogeneity may exist. Also, what's the proper cutoff that could predict the chemotherapy efficacy to a great extent? We are looking forward the future researches explore this relationship. Second, is the platinum-based chemotherapy the pure platinum and the toxal-based chemotherapy the pure toxal? $B R C A 1$ gene shows the different mechanism and efficacy in platinum and toxal regimens. As cell experiments suggest that low/negative BRCA1 benefit from platinum whereas high/negative BRCA1 benefit more from anti-tubulin regimen such as paclitaxel and docetaxel. But in practice, single 
agent in chemotherapy is impossible as the limited efficacy. Platinum is usually combined with anti-tubulin agents, for example, toxal and platinum (TP), docetaxel and carboplatin (DC). In our meta-analysis, we sorted the studies into platinum-based studies means that every patient received platinum agents (cisplatin, carboplatin or oxaliplatin), the toxal-based chemotherapy means that every patient received toxal contained agents (toxal, taxane or docetaxel). Although our meta-analysis showed that patients with low/negative BRCA1 have better objective response rate and longer OS and EFS, and patients with high/positive $B R C A 1$ have better ORR, the confounding factors from chemotherapy agents may exist in studies. Third, is BRCA1 an important predict or prognosis factor to the clinical outcome? Many factors may contribute to the ORR, OS as well as EFS, for example, age, smoking status, pathological type, tumor stage, the drug dosage and treatment cycle, also the genetic as well as gene-environment interaction also involve in disease progression, there were not enough baseline characters that ensure us to conduct stratified analysis. Four, were all relevant studies included in the analysis? This is impossible and difficult to assess. Although we searched and collected relevant studies until the December 10, 2012 to our best effort, there were still some studies with negative results did not presented the sufficient data and some were failed to get published. In our meta-analysis, only 3 Caucasian studies including 197 patients evaluated the ORR in platinum-based treatment. In toxal-based chemotherapy studies, only 4 studies consisted of 376 patients evaluated this association. The small sample size may mislead us and draw a wrong conclusion. Besides, except for one multi-center study [31], our included samples were mainly distributed in some countries in East-Asian (Chinese and Japanese) and European (Spanish, Greece). So few studies could we found in other countries such us USA, Canada, UK, German, France and so on. Also, the African population was limited. This disequilibrium of population distribution may also affect our results.

\section{Conclusions}

Despite the limitations of this meta-analysis, our study confirmed that low/negative BRCA1 expression was associated with better objective response rate (ORR) and longer overall survival (OS) and event-free survival (EFS) in NSCLC patients treated with platinumcontaining regimen, while high/positive BRCA1 level were associated with better objective response rate in toxal contained regimen. Therefore, BRCA1 might serve as a valuable marker for personal chemotherapy. However, considering the limitation our meta-analysis, multi-center of larger studies with hundreds or thousands of subjects and strict designed methodology was expected.

\section{Abbreviations}

BRCA1: Breast cancer susceptibility gene 1; NSCLC: Non-small-cell lung cancer; OR: Odds ratio; ORR: Objective response rate; OS: Overall survival; EFS: Event-free survival; PFS: Progression-free survival; DFS: Disease-free survival; TTP: Time to progression; RT-PCR: Reverse-transcriptase polymerase chain reaction; IHC: Immunohistochemistry.

\section{Competing interest}

The authors declare that they have no conflict of interest.

\section{Authors' contributions}

YYL and XL conceived and designed the study, YYL and XYL participated in selecting study, extracting data, performing the statistical analysis and drafting the manuscript. $X L$ has been involved in revising the manuscript critically for important intellectual content. All authors read and approved the final manuscript.

\section{Funding}

This reseach was supported by Guangxi Scientific reseach and technology development projects (Grant No.10124001A-44).

\section{Author details}

'Department of Cardiothoracic Surgery, the First Affiliated Hospital of Guangxi Medical University, Nanning, Guangxi Zhuang Autonomous Region 530021, China. ${ }^{2}$ Department of Urology, the First Affiliated Hospital of Guangxi Medical University, Nanning, Guangxi Zhuang Autonomous Region 530021, China.

Received: 22 January 2013 Accepted: 8 March 2013

Published: 15 March 2013

\section{References}

1. Jemal A, Siegel R, Xu J, Ward E: Cancer statistics, 2010. CA Cancer J Clin 2010, 60:277-300.

2. Siegel R, DeSantis C, Virgo K, Stein K, Mariotto A, Smith T, Cooper D, Gansler T, Lerro C, Fedewa S, Lin C, Leach C, Cannady RS, Cho H, Scoppa S, Hachey M, Kirch R, Jemal A, Ward E: Cancer treatment and survivorship statistics, 2012. CA Cancer J Clin 2012, 62:220-241

3. Custodio AB, Gonzalez-Larriba JL, Bobokova J, Calles A, Alvarez R, Cuadrado E, Manzano A, Diaz-Rubio E: Prognostic and predictive markers of benefit from adjuvant chemotherapy in early-stage non-small cell lung cancer. J Thorac Oncol 2009, 4:891-910.

4. Hall JM, Lee MK, Newman B, Morrow JE, Anderson LA, Huey B, King MC: Linkage of early-onset familial breast cancer to chromosome 17q21. Science 1990, 250:1684-1689.

5. Miki Y, Swensen J, Shattuck-Eidens D, Futreal PA, Harshman K, Tavtigian S, Liu Q, Cochran C, Bennett LM, Ding W, et al: A strong candidate for the breast and ovarian cancer susceptibility gene BRCA1. Science 1994, 266:66-71.

6. De Ligio JT, Velkova A, Zorio DA, Monteiro AN: Can the status of the breast and ovarian cancer susceptibility gene 1 product (BRCA1) predict response to taxane-based cancer therapy? Anticancer Agents Med Chem 2009, 9:543-549.

7. Quinn JE, Kennedy RD, Mullan PB, Gilmore PM, Carty M, Johnston PG, Harkin DP: BRCA1 functions as a differential modulator of chemotherapyinduced apoptosis. Cancer Res 2003, 63:6221-6228.

8. Lafarge $S$, Sylvain $V$, Ferrara M, Bignon YJ: Inhibition of BRCA1 leads to increased chemoresistance to microtubule-interfering agents, an effect that involves the JNK pathway. Oncogene 2001, 20:6597-6606.

9. Wang L, Wei J, Qian X, Yin H, Zhao Y, Yu L, Wang T, Liu B: ERCC1 and BRCA1 mRNA expression levels in metastatic malignant effusions is associated with chemosensitivity to cisplatin and/or docetaxel. BMC Cancer 2008, 8:97.

10. Taron M, Rosell R, Felip E, Mendez P, Souglakos J, Ronco MS, Queralt C, Majo J, Sanchez JM, Sanchez JJ, Maestre J: BRCA1 mRNA expression levels as an indicator of chemoresistance in lung cancer. Hum Mol Genet 2004, 13:2443-2449.

11. Mantel $N$, Haenszel W: Statistical aspects of the analysis of data from retrospective studies of disease. J Natl Cancer Inst 1959, 22:719-748.

12. DerSimonian R, Laird N: Meta-analysis in clinical trials. Control Clin Trials 1986, 7:177-188. 
13. Parmar MK, Torri V, Stewart L: Extracting summary statistics to perform metaanalyses of the published literature for survival endpoints. Stat Med 1998, 17:2815-2834

14. Higgins JP, Thompson SG, Deeks JJ, Altman DG: Measuring inconsistency in meta-analyses. BMJ 2003, 327:557-560

15. Begg CB, Mazumdar M: Operating characteristics of a rank correlation test for publication bias. Biometrics 1994, 50:1088-1101.

16. Ota S, Ishii G, Goto K, Kubota K, Kim YH, Kojika M, Murata Y, Yamazaki M, Nishiwaki Y, Eguchi K, Ochiai A: Immunohistochemical expression of BCRP and ERCC1 in biopsy specimen predicts survival in advanced non-small -cell lung cancer treated with cisplatin-based chemotherapy. Lung Cancer 2009, 64:98-104.

17. Shang XB, Yu ZT, Tang P, Zhang XZ: Study on the relationships of DNA repair associated proteins and cisplatin resistance in lung cancer. Shandong Medical Journal 2009, 49:25-27.

18. Yang JQ, Wang HB, Liu HX: Expression of BRCA1 in non-small cell lung cancer and its significance in prognosis. China Tropical Medicine 2009, 9:1705-1707.

19. Shan L, Han ZG, Liu L, Aerxiding P, Wang XG, Ma L, Wang Q, Zhang Y: ERCC1 and BRCA1 expressions in advanced non-small cell lung cancer and their relationship with cisplatin resistance. Tumor 2009, 29:571-574.

20. Wang LR, Zhang GB, Chen J, Li J, Li MW, Xu N, Shen Tu JZ: Effect of RRM1 and BRCA1 Expressions on Efficiency of Gemcitabine and Platinum in Patients with Advanced Non-Small Cell Lung Cancer. Chin Pharm J 2010, 45:1577-1580

21. Lu XM, Mao GX, Jie HM: Expression of BRCA1 in non small cell lung cancer and its relationship with platinum-based chemotherapy sensitivity. J Prac Med 2010, 26:3526-3528.

22. Mo HW, Li LP, Liu Q, Huang L: ERCC1, BRCA1, RRM1 expression and the relationship between platinum-based chemotherapy in advanced NSCLC patients. Chin J Clin Res 2011, 24:283-284.

23. Gao ZQ, Han BH, Shen J, Gu AQ, Qi DJ, Huang JS, Shi CL, Xiong LW, Zhao $Y Z$, Jiang LY, Wang HM, Chen YR: Expression of ERCC1, RRM1 and BRCA1 in tissues of advanced non-small cell lung cancer. J Shanghai Jiaotong Univ (Medical Science) 2011, 31:290-294.

24. Wan YY, Hui HX, Wang XW, Sun SA, Wu J: The correlation between chemotherapeutic efficacy and breast cancer susceptibility gene 1 and class III beta-tubulin protein expression in non-small cell lung cancer patients. Chin J Inter Med 2011, 50:469-473.

25. Zhang L, Liu T, Zhang JQ: Relationship between the protein expression of ERCC1, BRCA, beta-tubulin and K-ras and the efficacy and prognosis in advanced non-small cell lung cancer. Chin J Oncol 2011, 33:212-216.

26. Joerger M, De Jong D, Burylo A, Burgers JA, Baas P, Huitema AD, Beijnen JH, Schellens JH: Tubulin, BRCA1, ERCC1, Abraxas, RAP80 mRNA expression, p53/p21 immunohistochemistry and clinical outcome in patients with advanced non small-cell lung cancer receiving first-line platinumgemcitabine chemotherapy. Lung Cancer 2011, 74:310-317.

27. Fujii T, Toyooka S, Ichimura K, Fujiwara Y, Hotta K, Soh J, Suehisa H, Kobayashi N, Aoe M, Yoshino T, Kiura K, Date H: ERCC1 protein expression predicts the response of cisplatin-based neoadjuvant chemotherapy in non-small-cell lung cancer. Lung Cancer 2008, 59:377-384.

28. Gu HY, Xiang HF, Xin FJ, Hu YJ: Expression of ERCC1 and BRCA1 AND Their relationship with curative effect in non-small cell lung cancer after platium-based neoadjuvant chemotherapy. Med J Qilu 2012, 27:98-100.

29. Papadaki C, Sfakianaki M, loannidis G, Lagoudaki E, Trypaki M, Tryfonidis K, Mavroudis D, Stathopoulos E, Georgoulias V, Souglakos J: ERCC1 and BRAC1 mRNA expression levels in the primary tumor could predict the effectiveness of the second-line cisplatin-based chemotherapy in pretreated patients with metastatic non-small cell lung cancer. $J$ Thorac Oncol 2012, 7:663-671.

30. Zeng W, Shan L, Patiguli, Han ZG, Liu L, Ma L, Wang Q, Zhang Y: Expression of BRCAl and the correlation with chemotherapy and prognosis in nonsmall cell lung cancer after surgery. Chin Clin Oncol 2010, 15:1070-1073.

31. Pierceall WE, Olaussen KA, Rousseau V, Brambilla E, Sprott KM, Andre F, Pignon JP, Le Chevalier T, Pirker R, Jiang C, Filipits M, Chen Y, Kutok JL, Weaver DT, Ward BE, Soria JC: Cisplatin benefit is predicted by immunohistochemical analysis of DNA repair proteins in squamous cell carcinoma but not adenocarcinoma: theranostic modeling by NSCLC constituent histological subclasses. Ann Oncol 2012, 23:2245-2252.

32. Leng XF, Chen MW, Xian L, Dai L, Ma GY, Li MH: Combined analysis of mRNA expression of ERCC1, BAG-1, BRCA1, RRM1 and TUBB3 to predict prognosis in patients with non-small cell lung cancer who received adjuvant chemotherapy. J Exp Clin Cancer Res 2012, 31:25.

33. Chen $R$, Chen $R$, Shan L: Expression of ERCC 1 and BRCA1 in advanced Non small cell lung cancer and its clinical significance. J Xinjiang Med Univ 2011, 34:1362-1365.

34. Su C, Zhou S, Zhang L, Ren S, Xu J, Zhang J, Lv M, Zhou C: ERCC1, RRM1 and BRCA1 mRNA expression levels and clinical outcome of advanced non-small cell lung cancer. Med Oncol 2011, 28:1411-1417.

35. Papadaki C, Tsaroucha E, Kaklamanis L, Lagoudaki E, Trypaki M, Tryfonidis K, Mavroudis D, Stathopoulos E, Georgoulias V, Souglakos J: Correlation of BRCA1, TXR1 and TSP1 mRNA expression with treatment outcome to docetaxel-based first-line chemotherapy in patients with advanced/ metastatic non-small-cell lung cancer. Br J Cancer 2011, 104:316-323.

36. Boukovinas I, Papadaki C, Mendez P, Taron M, Mavroudis D, Koutsopoulos A, Sanchez-Ronco M, Sanchez JJ, Trypaki M, Staphopoulos E, Georgoulias V, Rosell R, Souglakos J: Tumor BRCA1, RRM1 and RRM2 mRNA expression levels and clinical response to first-line gemcitabine plus docetaxel in non-small-cell lung cancer patients. PLoS One 2008, 3:e3695.

37. Zhou ZS, Liao XF, Zheng QH, He HJ: Expression of Survivin, BRCA1 and class III $\beta$-tubulin in Non-small Cell Lung Cancer and Its Relationship with Resistance to Paclitaxel. J Chin Oncol 2012, 18:806-810.

38. Chabalier C, Lamare C, Racca C, Privat M, Valette A, Larminat F: BRCA1 downregulation leads to premature inactivation of spindle checkpoint and confers paclitaxel resistance. Cell Cycle 2006, 5:1001-1007.

39. Yarden RI, Papa MZ: BRCA1 at the crossroad of multiple cellular pathways: approaches for therapeutic interventions. Mol Cancer Ther 2006, 5:1396-1404

40. Wu JX, LU LY, Yu XC: The role of BRCA1 in DNA damage response. Protein Cell 2012, 1:117-123.

41. Rosell R, Perez-Roca L, Sanchez JJ, Cobo M, Moran T, Chaib I, Perez-Roca L, Szymanowska A, Rzyman W, Puma F, Kobierska-Gulida G, Farabi R, Jassem J: Customized treatment in non-small-cell lung cancer based on EGFR mutations and BRCA1 mRNA expression. PLoS One 2009, 4:e5133.

42. Su T, Zhao LJ, Chang WJ, Wang GP, He YC, Sun QY, Zhang HW, Li Q, Cao GW: Relationship of ERCC1, XPD, and BRCA1 polymorphisms with eff icacy of platinum - based chemotherapy for patients with advanced non-small cell lung cancer. Acad J Sec Mil Med Univ 2010, 31:117-122.

43. Kim HT, Lee JE, Shin ES, Yoo YK, Cho JH, Yun MH, Kim YH, Kim SK, Kim HJ, Jang TW, Kwak SM, Kim CS, Ryu JS: Effect of BRCA1 haplotype on survival of non-small-cell lung cancer patients treated with platinum-based chemotherapy. J Clin Oncol 2008, 26:5972-5979.

\section{doi:10.1186/1756-9966-32-15}

Cite this article as: Yang et al:: Breast cancer susceptibility gene 1

$(B R C A 1)$ predict clinical outcome in platinum- and

toxal-based chemotherapy in non-small-cell lung cancer (NSCLC)

patients: a system review and meta-analysis. Journal of Experimental \& Clinical Cancer Research 2013 32:15.

\section{Submit your next manuscript to BioMed Central and take full advantage of:}

- Convenient online submission

- Thorough peer review

- No space constraints or color figure charges

- Immediate publication on acceptance

- Inclusion in PubMed, CAS, Scopus and Google Scholar

- Research which is freely available for redistribution 